\title{
To study biochemical markers in chronic obstructive pulmonary disease patients
}

\author{
Sandeep Kumar Sharma ${ }^{1}$, Niranjan Singh ${ }^{2, *}$, K.V. Thimmaraju ${ }^{3}$, Mona Tilak ${ }^{4}$ \\ ${ }^{\mathbf{1}}$ Associate Professor, ${ }^{2}$ Assistant Professor, ${ }^{3}$ Professor, Dept. of Biochemistry, Varun Arjun Medical College, Shahjahanpur, Uttar \\ Pradesh, ${ }^{4}$ Professor, Dept. of Biochemistry, Dr. D.Y. Patil Medical College Pune, Maharashtra India
}

\author{
*Corresponding Author: Niranjan Singh \\ Email: niranjandugtal@gmail.com
}

Received: $20^{\text {th }}$ July, 2018

Accepted: $1^{\text {st }}$ August, 2018

\begin{abstract}
Introduction: Chronic obstructive pulmonary disease (COPD) which includes chronic bronchitis and emphysema is considered as a progressive type of respiratory tract disease and is characterized by structural changes such as emphysema, airflow limitation, dynamic hyperinflation, air trapping, and peribronchial fibrotic remodeling of the lungs with significant systemic inflammatory components, induced by chronic exposures to smoking and/or occupational or environmental sources.

Materials and Methods: This case control study was conducted on 60 subjects in which 30 were healthy controls and 30 were cases of COPD. Patients with history of respiratory disease other than COPD, cardiac diseases and neuromuscular disease were excluded. 30 healthy age and gender matched non-smoker adults were selected as control group.

Results: Unpaired t test was performed and it was observed that Total Cholesterol, Triglyceride, Low Density Lipoprotein, Lactate dehydrogenase levels were significantly higher and serum concentrations of High Density Lipoprotein was decreased significantly in cases as compared to controls.

Conclusion: Serum LDH levels are altered in many respiratory diseases but it has not been studied in depth in COPD patients. In view of this we conducted the study and our results shows that patients with COPD have raised serum LDH levels.
\end{abstract}

Keywords: Smoking, COPD, Lactate dehydrogenase.

\section{Introduction}

Chronic obstructive pulmonary disease (COPD) affects 210 million people worldwide and kills > 4 million people every year, accounting for around $9 \%$ of total deaths. Ninety percent of these mortalities occur in low- and middle-socio economic countries. It is projected to be the $3^{\text {rd }}$ leading cause of death by $2030 .{ }^{1}$ Its chronic nature causes disruption of normal social roles, reduced workability, and poses massive burden on direct and indirect costs. ${ }^{2}$

According to the World Health Organization report, the prevalence of COPD ranges between $4 \%$ and $20 \%$ in the Indian adults. ${ }^{1}$ According to a recent systematic review which includes estimates from the Indian Study on Epidemiology of Asthma, Respiratory Symptoms and Chronic Bronchitis (INSEARCH) ${ }^{3}$ and other major studies in India, the prevalence of Chronic Bronchitis seems to range between $6.5 \%$ and $7.7 \%$ in rural and up to $9.9 \%$ in urban India. The review also mentions that the included studies were mostly low quality, questionnaire-based and was conducted around 1990-2006. These figures may underestimate the true burden of COPD since questionnaire-based prevalence estimates tend to be lower than the true spirometrybased estimates. ${ }^{4}$ this review provides the best available estimate of COPD prevalence till date but is unlikely to reflect the current disease burden across all Indian sub populations. $^{5}$

Lactate dehydrogenase ( $\mathrm{LDH})$ is the isoenzyme that is intracytoplasmic in location and is universally present in all cells of the body to varying extent. It has five types of isoenzyme activity present in the blood.
Elevation in respective $\mathrm{LDH}$ isoenzymes level is organ specific. LDH-1, LDH-2 are isolatedely elevated in heart, kidneys, erythrocytes and brain disorders while LDH-3 is elevated in the disorder of the disorder of lungs, thyroid, pancreas, adrenals, and leukocytes; similarly LDH-4 level is increased in disorders of skeletal muscles injury and the LDH-5 in hepatic system disorder.

$\mathrm{LDH}$ present in normal concentration in blood is the result of normal tissue breakdown which increases significantly after major tissue damage. LDH being a cytoplasmic cellular enzyme if increased in serum serve as marker suggesting that there is cellular injury induced by pathological conditions. ${ }^{6}$ Rise in $\mathrm{LDH}$ is seen in inflammatory conditions with or without cell damage. ${ }^{7}$ Hematological disorders like hemolytic anemia, myocardial infarction, liver diseases and several respiratory conditions including pulmonary tuberculosis, bronchial asthma, chronic obstructive pulmonary disease (COPD) all have altered level of LDH levels.

The previous studies on lipid profile shows contradictory findings in the COPD patients. Looking at previous studies, our study was done to investigate the lipid profile levels in the COPD patients.

\section{Materials and Methods}

This case control study was performed in the Department of Clinical Biochemistry at Varun Arjun Medical College and Rohilkhand Hospital, Banthra, Shahjahanpur U.P. For this study patients were selected from the O.P.D. of respiratory medicine and a total of 
30 COPD patients were included along with 30 healthy controls were enrolled for this study.

The inclusion criteria includes

1. COPD patients irrespective of duration of disease

2. COPD patients irrespective of history of smoking The exclusion criteria includes

1. Those patients who do not want to enroll

2. Terminally ill patients

3. Known case of diabetes, hypertension, any other respiratory disease

4. Subjects on any hypolipidemic drugs.

Informed consent was obtained from all the patients. Subsequently, the diagnosis of COPD was made by guidelines laid by the Global initiative for obstructive lung disease $(\mathrm{GOLD})^{7}$ criteria with risk factors such as dyspnea, chronic cough, chronic sputum production, history of exposure to the respective risk factors i.e. smoking, and age > 40 years. Detailed history was taken from all the patients followed by clinical examination and radiological tests were performed to confirm the presence of COPD and the associated cardiovascular complications.

For sample collection, patients were asked to come next morning in overnight fasting state and $5 \mathrm{ml}$ fasting blood sample was drawn from anticubital vein and collected in red-top plain vacutainer from all the participants. Sample was then allow to clot for 15 to 25 minutes and centrifuged at $3000 \mathrm{rpm}$ for 10 minutes Serum samples were separated immediately and analyzed on the same day. Samples which are hemolysed and lipemic were excluded. For estimation of Total Cholesterol method formulated by Allain ${ }^{8}$ et al was used, for triglyceride Glycerol phosphate oxidase $^{9,10}$ method was used and for HDL polyvinyl sulfonic acid (PVS)/ polyethylene-glycol-methyl ether $(\mathrm{PEGME})^{11}$ method was used. For the estimation of Lactate dehydrogenase (LDH) Henry ${ }^{12}$ et al method was used. All these parameters were estimated on ERBA EM-200 fully auto analyzer. LDL and VLDL was measured by formula method.

\section{Statistical Methods}

Student $t$ test was used for statistical analysis of the data, for statistical analysis SPSS version 21.0 was used and $\mathrm{p}$ value $<0.05$ was considered significant.

\section{Results}

Mean age in COPD patients was 39.20 \pm 12.50 years and control patients was $39.80 \pm 11.74$ years and age range was 20-60 years. Both groups were well matched for age and sex distribution.

Table 1: Comparision of lipid profile in case and controls

\begin{tabular}{|l|c|c|c|}
\hline \multicolumn{1}{|c|}{ Parameters } & $\begin{array}{c}\text { Cases }(\mathbf{n}=\mathbf{3 0}) \\
\text { Mean } \pm \text { SD }\end{array}$ & $\begin{array}{c}\text { Controls }(\mathbf{n}=30) \\
\text { Mean } \pm \text { SD }\end{array}$ & p-value \\
\hline $\begin{array}{l}\text { Mean Total cholesterol } \\
(120-200 \mathrm{mg} / \mathrm{dl})\end{array}$ & $184.50 \pm 22.10$ & $172.20 \pm 14.20$ & $<0.05$ \\
\hline $\begin{array}{l}\text { Mean LDL } \\
(50-170 \mathrm{mg} / \mathrm{dl})\end{array}$ & $117.30 \pm 11.80$ & $111.50 \pm 11.10$ & $<0.05$ \\
\hline $\begin{array}{l}\text { Mean HDL } \\
(35-70 \mathrm{mg} / \mathrm{dl})\end{array}$ & $33.60 \pm 5.20$ & $38.90 \pm 5.40$ & $<0.05$ \\
\hline $\begin{array}{l}\text { Mean Triglycerides } \\
(50-160 \mathrm{mg} / \mathrm{dl})\end{array}$ & $147.50 \pm 13.50$ & $132.10 \pm 11.80$ & $<0.05$ \\
\hline
\end{tabular}

Unpaired t test was performed and it was observed that TC, TG, LDL levels were significantly higher and serum concentrations of HDL were decreased significantly in cases as compared to controls.

Table 2: Mean LDH level in cases and controls

\begin{tabular}{|l|c|c|c|}
\hline \multicolumn{1}{|c|}{ Parameters } & Cases $(\mathbf{n}=\mathbf{3 0})$ & Controls $(\mathbf{n}=\mathbf{3 0})$ & p-value \\
\hline $\begin{array}{l}\text { Serum LDH (U/L) } \\
(225-450 \text { U/L) }\end{array}$ & $344.80 \pm 71.40$ & $291.50 \pm 80.20$ & $<0.05$ \\
\hline
\end{tabular}

The statistically significant increased value of serum lactate dehydrogenase in cases as compared to control group with $\mathrm{p}$ value $<0.05$ (two tailed $\mathrm{p}$ value).

$\mathrm{p}$ value $<0.05$ is considered to be statistically significant.

\section{Discussion}

Along with significant increased morbidity and mortality COPD also precipitates dyslipidemia. So present study was conducted and it was observed that TC, TG, LDL levels were significantly higher but there was significant decrease in the serum HDL level in cases as compared to controls. This alteration in the levels of TC, TG, LDL and HDL was in the same trend as seen in the results of some previous studies. ${ }^{13,14}$

The result of our study and the study conducted by Kamat SR, et al differ from each other as their results showed that lipid profile doesn't alter in COPD patients. ${ }^{15}$ Smoking is a major risk factor of dyslipidemia and on the other hand it is simultaneously a major etiological factor for COPD also. Serum level of total cholesterol, TG, LDL is seen to be increased in 
smokers as compared to nonsmokers where as HDL is decreased in smokers. ${ }^{16}$

Nicotine present in the tobacco stimulates the adrenal gland which gives rise to hypersecretion of adrenaline from the adrenal gland. Due to this sympathetic stimulation there is increased adipolysis in the adipose tissue of the body. Thus there is rise in the serum concentration of free fatty acids (FFA). This rise in the concentration of the free fatty acidfurther stimulatesthe hepatic synthesis and secretion of cholesterol and Very Low Density Lipoprotein and hence increased TG. Cigarette smoking increases the resistance of insulin hormone on target tissue and increases the levels of LDL, VLDL and TG are seen in this hyperinsulinemic conditions because of the decreased activity of lipoprotein lipase ${ }^{17}$.Our study which suggests that TC,TG and LDL level increases in COPD patients while HDL level decreases which is correlating well with other studies. ${ }^{18-20}$

Patients suffering from COPD was having significant rise in LDH levels when compared to nonsmoker controls. Further it was found that it is the predominant increase in serum LDH 3 isoenzymes of the respiratory tract origin which increases the total LDH level..$^{21}$ Pathological changes are observed in the mucosa of the respiratory tract of the chronic cough mucosa includes increased broncho-alveolar mast cells, mononuclear phagocytic cells and epithelial shedding. In addition it is also observed that the patients suffering from chronic cough also have the homogenous rise in cellular markers of inflammation in the bronchoalveolar lavage fluid. ${ }^{22}$

It is possible that persistent coughing may itself induce a degree of inflammation because of the injury of the epithelium of the respiratory tract as well as that of the lung parenchyma. It is likely that the inflammatory process in patients with chronic cough is the cause of the increase in LDH.

\section{Conclusion}

Serum levels of TC, TG, LDL, LDH were significantly higher in COPD patients and serum concentrations of HDL were also decreased significantly compared to controls.

\section{References}

1. World Health Organization. Global Surveillance, Prevention and Control of Chronic Respiratory Diseases: A Comprehensive Approach. Geneva, Switzerland: World Health Organization; 2007.

2. Johnson JL, Campbell AC, Bowers M, Nichol AM. Understanding the social consequences of chronic obstructive pulmonary disease: The effects of stigma and gender. Proc Am Thorac Soc. 2007;4:680-2

3. McKay AJ, Mahesh PA, Fordham JZ, Majeed A. Prevalence of COPD in India: A systematic review. Prim Care Respir J. 2012;21:313-21.

4. Kumar N, Gupta N, Kishore J. Kuppuswamy's socioeconomic scale: Updating income ranges for the year 2012. Indian J Public Health. 2012;56:103-4.
5. Radha TG, Gupta CK, Singh A, Mathur N. Chronic bronchitis in an urban locality of New Delhi - an epidemiological survey. Indian J Med Res. 1977;66:27385.

6. Hagadorn JE, Bloor CM, Yang MS. Elevated plasma activity of lactate dehydrogenase isoenzyme-3 (LDH3) in experimentally-induced immunologic lung injury. Am J Pathol. 1971;64:575-584.

7. The Global Strategy for the Diagnosis, Management and Prevention of COPD, Global Initiative for Chronic Obstructive Lung Disease (GOLD) 2017. Available from: https://goldcopd.org.

8. Allain, C.C.Poon, L.S. Chan, C.S.G. Richmond, W and $\mathrm{Fu}$, P.C. Enzymatic determination of total serum cholesterol. Clin Chem.1974;20:470-475.

9. Fossati, P. Prencipe, L. Serum triglycerides determined colorimetrically with an enzyme that produces hydrogen peroxide. Clin. Chem. 1982:28:2077-80.

10. Trinder, P. Trinder, P. Enzymatic colorimetric determination of triglycerides by GPO-PAP method. Ann Clin Biochem, 6:24-27. 1969. Ann Clin Biochem. 1969:6:24-27.

11. Pisani T, Gebski CP, Leary. Accurate Direct Determination of Low-Density Lipoprotein Cholesterol Assay. Arch Pathol Lab Med. 1995;119:1127.

12. Henry R.J, Chiamori N, Golub O.J. and Berkman S. Revised spectrophotometric methods for the determination of glutamic- oxalacetic transaminase, glutamic-pyruvic transaminase and lactic acid dehydrogenase. Am J Clin Path. 1960;34:381-98.

13. Chatila WM, Thomashow BM, Minai OA, Criner GJ, Make BJ. Co morbidities in chronic obstructive pulmonary disease. Proc Am Thorac Soc. 2008;4:549-55.

14. Begum K, Begum MK, Sarker ZH, Dewan MRK, Siddique MJH. Lipid profile status of chronic obstructive pulmonary disease in hospitalized patients. Bangladesh $J$ Med Biochem. 2010; 3(2):42-45.

15. Nillawar AN, Joshi KB, Patil SB, Bardapurkar JS, Bardapurkar SJ. Evaluation of HS-CRP and Lipid Profile in COPD. J Clin Diagn Res. 2013;7:801-3.

16. Ebrahimi M, Kazemi-Bajestani SM, Ghayour-Mobarhan M, Moohebati M, Paydar R, Azimi-Nezhad M, et al. Metabolic syndrome may not be a good predictor of coronary artery disease in the Iranian population: Population-specific definitions are required. Scientific World Journal. 2009;9:86-96.

17. Rao MV, Raghu S, Kiran S, Rao CH. A study of lipid profile in chronic obstructive pulmonary disease. $J$ of Evolution of Med and Dent Sci. 2015;4(42):7287-7296. DOI: $10.14260 /$ jemds/2015/1059.

18. Gupta R, Bhadoria DP, Mittal A, Bhandoria P, Gupta S Lipid profile in obstructive airway disorders. J Assoc Physicians India. 2002;50:186-87.

19. Begum K, Begum MK, Sarker ZH, Dewan MRK, Siddique MJH. Lipid profile status of chronic obstructive pulmonary disease in hospitalized patients. Bangladesh J Med Biochem. 2010;3(2):42-45.

20. Ritabrata Mitra, Subinay Datta, Mrinal Pal, Kaushik Ghosh, Debajoity Paul and Keya Pal. Lipid Profile Status in Chronic Obstructive Pulmonary Disease and Association with Interleukin 8. BJMMR. 2015;9(7):1-7.

21. McGarvey LP, Forsythe P, Heaney LG, J MacMahon, M Ennis. Bronchoalveolar lavage findings in patients with chronic nonproductive cough. Eur Respir J. 1999;13:5965 . 
22. Jatakanon A, Lalloo UG, Lim S, Peter J Barnes.

Increased neutrophils and cytokines, TNF-alpha and IL-8, in induced sputum of non-asthmatic patients with chronic dry cough. Thorax. 1999;54:234-7.

How to cite this article: Sharma S. K, Singh N, Thimmaraju K.V, Tilak M. To study biochemical markers in chronic obstructive pulmonary disease patients. Int J Clin Biochem Res. 2018;5(4):627-630. 